ORIGINAL ARTICLE

\title{
Activation of the extracellular signal regulated kinase (ERK) pathway in human melanoma
}

\author{
L Zhuang, C S Lee, R A Scolyer, S W McCarthy, A A Palmer, X D Zhang, J F Thompson, L P Bron, \\ P Hersey
}

J Clin Pathol 2005;58:1163-1169. doi: 10.1136/jcp.2005.025957

See end of article for authors' affiliations

....................

Correspondence to: Professor P Hersey, Oncology and Immunology Unit, Room 443, David Maddison Clinical Sciences Building, Newcastle Mater Misericordiae Hospital, Cnr King and Watt Streets, Newcastle, NSW 2300,

Australia; Peter.Hersey@ newcastle.edu.au

Accepted for publication 29 March 2005
Background: Several studies suggest that melanoma may be resistant to treatment because of resistance to apoptosis and that this may be the result of activation of the extracellular signal regulated kinase (ERK1/2) pathway.

Aims: To test this hypothesis by examining the expression of ERK $1 / 2$ and its activated form in histological sections of melanoma and its relation to known prognostic features of the disease.

Materials/Methods: Immunohistochemistry with antibodies to ERK1/2 and phosphorylated ERK (p-ERK) was performed on formalin fixed sections from 42 primary melanomas, 38 metastases, and 20 naevi. Fourteen of the primary melanomas were in the radial and 28 in the vertical growth phase.

Results: ERK1/2 was widely expressed (100\%) in all the (pigmented) lesions studied. p-ERK1/2 expression was much lower in compound (32.4\%) and dysplastic (54.5\%) naevi than in primary melanoma (nodular $78.8 \%$, superficial spreading $67 \%$ ) and subcutaneous metastases (76.3\%). p-ERK expression was much lower in lymph node metastases $(48.5 \%)$, suggesting that the microenvironment may influence the activation of ERK. There was a (non-significant) trend for $p$-ERK expression to be higher in thick $(>1.0 \mathrm{~mm})$ versus thin $(\leqslant 1.0 \mathrm{~mm})$ melanoma $(p=0.23)$. There was a trend for overall survival to be related to $\mathrm{p}$-ERK expression in patients with melanoma over $1 \mathrm{~mm}$ in thickness.

Conclusions: Expression of activated ERK1/2 in melanocytic lesions appears to be related to malignant potential so that activation of ERK1/2 may be important in melanoma progression. These results provide important histological support for the proposal that inhibition of this signalling pathway may be useful in treatment of melanoma.

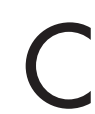
utaneous melanoma is a malignant neoplasm of melanocytes and is an important cause of morbidity and mortality in Western countries that have predominantly white populations. ${ }^{12}$ It ranks as the third most common form of skin cancer in white skinned people, after basal cell carcinoma and squamous cell carcinoma, and continues to increase in incidence despite ongoing public health campaigns in many countries. In a proportion of patients melanoma appears to arise in association with naevi, particularly dysplastic or atypical naevi, indicating that naevi can be premalignant lesions.

"It is generally believed that chemotherapy kills cancer cells by induction of a final common pathway that leads to programmed cell death or apoptosis"

Various features of primary melanoma, including clinical characteristics such as the anatomic site of the tumour, patient age and sex, and pathological features of the primary tumour, such as its Breslow thickness, Clark's level, ulceration, dermal mitotic rate, satellite deposits, lymphocytic infiltration, and histological type, have been studied to determine their prognostic relevance. ${ }^{3}{ }^{4}$ The prognosis of thin melanoma is good ${ }^{5}$ and surgical resection in early stages is usually curative. However, once melanoma has spread beyond the skin and regional lymph nodes, it is frequently incurable by currently available chemotherapeutic and other agents. ${ }^{6}$ Although different forms of chemotherapy have several biochemical targets, it is generally believed that chemotherapy kills cancer cells by induction of a final common pathway that leads to programmed cell death or apoptosis characterised morphologically by cell shrinkage, chromatin condensation, and extensive nuclear and cellular fragmentation. ${ }^{78}$

One of the basic properties of cancer cells is thought to be their resistance to apoptosis, leading to their prolonged survival. ${ }^{10}$ Traditionally, two principal pathways to apoptosis are recognised: the transmembrane "extrinsic" pathway and the mitochondrial "intrinsic" pathway. Both are dependent on the activation of caspases and both are subjected to regulation by proapoptotic and antiapoptotic proteins of the Bcl-2 and inhibitor of apoptosis families. ${ }^{11-13}$ In previous studies on melanoma cell lines, we found that a common cause of resistance to apoptosis was activation of the mitogen activated protein kinase (MAPK) family and, in particular, extracellular signal regulated kinase $1 / 2\left(\right.$ ERKl/2). ${ }^{14}$ Similar results were found in studies on other cancers. ${ }^{15}{ }^{16}$ Activation of MAPK (ERKl/2) was detected more frequently in primary melanoma than in naevi, ${ }^{17}$ and introduction of activated MAPK kinase into melanocytes resulted in tumorigenesis in nude mice. ${ }^{18}$ In addition to inhibition of apoptosis, the ERKl/ 2 pathway also plays an important role in the regulation of cell division, as discussed elsewhere. ${ }^{19} 20$

In view of the potential importance of this signalling pathway as a cause of resistance to apoptosis and tumour progression, we investigated its importance in melanoma by immunohistological examination of its expression and activation to test the hypothesis that these features may be related to known prognostic features of melanoma, such as thickness and mitotic rate. The results support previous

Abbreviations: DFS, disease free survival; ERK, extracellular signal regulated kinase; IRS, immunoreactive score; MAPK, mitogen activated protein kinase; OS, overall survival; $p$-ERK, activated extracellular signal regulated kinase 
Table 1 Summary of the patient demographics and melanocytic lesions

\begin{tabular}{lcllc}
\hline & & & \multicolumn{2}{c}{ Sex } \\
\cline { 5 - 5 } Melanocytic lesions & $\mathbf{N}$ & Median age & Male & Female \\
\hline Compound naevus & 10 & 36.5 & 6 & 4 \\
Dysplastic naevus & 10 & 36.5 & 7 & 3 \\
Melanoma $\leqslant 1.0 \mathrm{~mm}$ & 18 & 67.5 & 7 & 11 \\
Melanoma $>1.0 \mathrm{~mm}$ & 24 & 69.5 & 21 & 3 \\
Subcutaneous metastasis & 21 & 74 & 12 & 9 \\
Lymph node metastasis & 17 & 60 & 9 & 8 \\
Total & 100 & & 62 & 38 \\
\hline
\end{tabular}

findings that activation of this pathway is common in melanoma, although a strong relation to existing prognostic factors was not seen.

\section{MATERIALS AND METHODS Patient material}

The tissue blocks of specimens from 100 patients were retrieved from the archival files of the department of anatomical pathology at Royal Prince Alfred Hospital, Sydney, Australia. These had been surgically excised during the period 2000-3. The cases consisted of (1) 42 primary cutaneous melanomas, including 18 nodular melanomas, 14 superficial spreading melanomas, four desmoplastic melanomas, three in situ melanomas, two acral lentiginous melanomas, and one lentigo maligna (Hutchinson's melanotic freckle) melanoma; (2) 21 subcutaneous melanoma metastases including two in fibrofatty tissue and one in skeletal muscle; (3) 17 lymph node metastases; (4) 10 dysplastic naevi; and (5) 10 compound naevi. Dysplastic naevi were diagnosed on the basis of histological criteria: (1) somewhat symmetrical, (2) uniform slight elongation of rete in the lentiginous compartment with bridging nests or anastomosing rete, (3) eosinophilic fibroplasia or lamellar fibroplasia present, (4) moderate cytological atypia, and (5) absence of mitoses in the dermis. ${ }^{21} 22$ The 42 primary cutaneous melanomas were from patients treated at the Sydney Melanoma Unit over the period December 2000 to March 2002. Haematoxylin and eosin stained sections of all 100 cases were reviewed by five of the authors (SWM, RAS, AAP, CSL, and LQZ). Depending on the Breslow thickness, primary melanomas were separated into thin $(\leqslant 1 \mathrm{~mm})$ and thick $(>1 \mathrm{~mm})$ melanomas and also according to radial and vertical growth phase, mitosis, Clark level, and cytological features. Samples of normal skin from adjacent tumours were included. All patients with melanoma had regular follow up at the Sydney Melanoma Unit. Median follow up was 43.5 months (range, 21-50).

\section{Immunohistochemistry}

Sections ( $5 \mu \mathrm{m}$ thick) were cut from formalin fixed, paraffin wax embedded tissue blocks. Sections were dewaxed in xylene and rehydrated through graded concentrations of alcohol. After three periods of microwave antigen retrieval in $0.01 \mathrm{~mol} /$ litre citrate buffer ( $\mathrm{pH} 6.0$ ) for five minutes each, ${ }^{23}$ they were incubated at room temperature for one hour with rabbit antihuman ERKI/2 antibody (polyclonal IgG; Santa Cruz, San Diego, California, USA) at a 1/1000 dilution in Tris buffer. For phosphorylated (activated) ERK (p-ERK) staining, antigen retrieval was carried out in a $100^{\circ} \mathrm{C}$ water bath

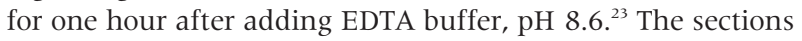
were then incubated with mouse antihuman p-ERK antibody (monoclonal IgG; Santa Cruz) at room temperature for one hour at a 1/100 dilution in Tris buffer. Binding of the primary antibodies was visualised using the Vectastain ABC kit
(Vector Laboratories, Burlingame, California, USA) and DAB kit (Dako, Carpenteria, California, USA). The sections were then stained with haematoxylin. Negative controls of mouse IgG/Tris buffer were included in each experiment. Staining of prostate and breast carcinoma were used as a positive control for ERKl/2 and p-ERK, respectively. ${ }^{24} 25$

The immunohistochemical score (IRS) for each case was determined by combining an estimate of the percentage of immunoreactive cells (quantity score) with an estimate of the staining intensity (intensity score). It was calculated by multiplying the percentage of positive cells divided by 10 by the intensity score. Staining intensity was scored on an arbitrary scale of $0-3$, where 0 was no staining, 1 was weak, 2 was moderate, and 3 was strong. The pattern of distribution (focal or diffuse) was also assessed for each case.

\section{Statistical analysis}

Statistical analysis was performed with Microsoft Excel 2000

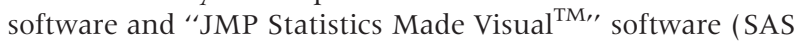
Institute Inc, Trunbull, Connecticut, USA). The correlation between ERKl/2 and p-ERK staining and groups of naevi and melanoma was performed using the one way ANOVA two tailed $t$ test. Comparisons for each pair were made using the Student's $t$ test and comparisons for all pairs using the Tukey-Kramer HSD method. The comparisons for p-ERK expression in nodular melanoma, desmoplastic melanoma, superficial spreading melanoma, dysplastic naevi, and compound naevi used the one way ANOVA two tailed $t$ test, the Student's $t$ test for each pair, and the Tukey-Kramer HSD multiple comparison tests; acral lentiginous melanoma, in situ melanoma, and lentigo maligna melanoma were excluded from this comparison because of the small numbers of these cases studied. The correlation between p-ERK expression in each primary melanoma and tumour Breslow thickness and mitotic rate was assessed using regression analysis.

Disease free survival (DFS) and overall survival (OS) were calculated using Kaplan-Meier estimates. Differences in DFS and OS between patients with melanoma according to tumour thickness ( $\leqslant 1 \mathrm{~mm}$ thickness and $>1$ mm thickness) and p-ERK expression (above and below the median \% value or above and below the IRS score) were compared using log rank and $\chi^{2}$ statistical methods. ${ }^{26}$ Other arbitrary cut off values for percentage of p-ERK positive cells and IRS score were also examined.

\section{RESULTS}

Table 1 shows the types of tumours and their corresponding patient demographics. The patients' ages ranged from 16 to 93 years and the median age was 66 years. Thirty eight $(38 \%)$ were female and sixty two (62\%) were male. For the 42 cases of primary melanoma, ages ranged from 23 to 84 years and the median age was 69 years. Fourteen were female and twenty eight were male. The Breslow thickness of the tumours ranged from 0.1 to $16 \mathrm{~mm}$. There were 24 cases of primary melanoma $>1 \mathrm{~mm}$ and 18 cases of primary melanoma $\leqslant 1 \mathrm{~mm}$ or 28 vertical growth phase and 14 radial growth phase cases.

As shown in fig 1, ERKl/2 was expressed to varying degrees in all cases. The percentages of positive cells ranged from $40 \%$ to $100 \%$. The mean percentages of positive cells in dysplastic naevi, thin melanomas, and thick melanomas were $99.6 \%, 98.9 \%$, and $84.1 \%$, respectively (table 2). ERK1/2 appeared to be expressed in both the cytoplasm and nucleus of melanocytic cells. The distribution of staining was diffuse rather than focal and ranged in intensity from 1 to 3 (fig 1AF). Only low amounts of ERKL/2 were detected in melanocytes of normal skin (fig $1 G$ ). In seven of 24 cases of thick 

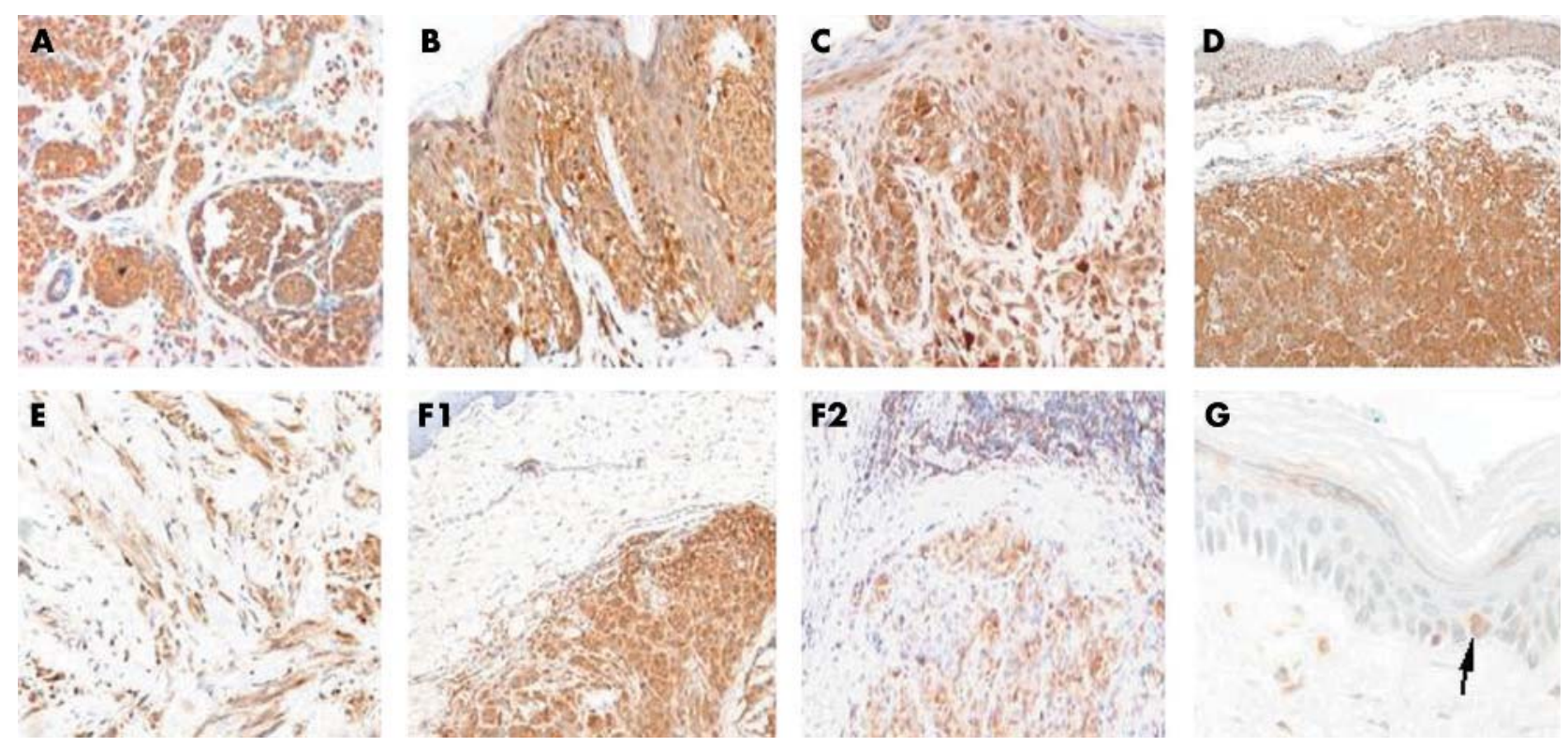

Figure 1 Extracellular signal regulated kinase 1/2 expression in different types of primary and secondary melanocytic tumours. (A) Compound naevus; positive cells, 80\%; immunoreactive score (IRS), 16; original magnification, $\times 100$. (B) Dysplastic naevus; positive cells, 100\%; IRS, 20; original magnification, $\times 200$. (C) Melanoma $\leqslant 1.0 \mathrm{~mm}$; positive cells, 100\%; IRS, 30; original magnification, $\times 200$. (D) Melanoma $>1.0 \mathrm{~mm}$; positive cells, 98\%; IRS, 19.6; original magnification, $\times 100$. (E) Desmoplastic melanoma; positive cells, 90\%; IRS, 18; original magnification, $\times 200$. (F) Metastatic melanoma: (1) subcutaneous metastasis; positive cells, 100\%; IRS, 30; original magnification, $\times 100$; (2) lymph node metastasis; positive cells, $85 \%$; IRS, 12.8; original magnification, $\times 100$. (G) Normal skin melanocytes; positive cells, $<2 \%$; IRS, $<2$ (arrow); original magnification, $\times 400$.

melanoma, ERK1/2 expression was more intense at the deep margin of the tumour.

p-ERK was expressed in 95 melanomas and naevi, with the percentage of positively staining cells ranging from $5 \%$ to $100 \%$. The mean percentages of cells positive for p-ERK in compound naevi, dysplastic naevi, thin melanomas, thick melanomas, and subcutaneous melanoma metastases were $32.4 \%, 54.5 \%, 64.6 \%, 77.1 \%$, and $76.3 \%$, respectively. These differences were highly significant using the one way ANOVA two tailed $t$ test $(\mathrm{p}<0.0005$; table 2$)$. The mean percentage of cells in thick melanomas with activated p-ERK was higher than in dysplastic naevi $(p<0.01)$, compound naevi $(\mathrm{p}<0.0001)$, and lymph node metastases $(\mathrm{p}<0.005)$ using the Student's $t$ test, and was higher than in compound naevi $(p<0.0001)$ and lymph node metastases $(p<0.005)$ (fig 2$)$ using the Tukey-Kramer method for multiple comparisons. In patients with metastatic melanoma, p-ERK was expressed in a higher percentage of cells in subcutaneous metastases compared with lymph node metastases $(p<0.005)$ and compound naevi $(\mathrm{p}<0.001)$ (fig 2). The distribution of positive cells was heterogeneous. The staining intensity was weaker in benign lesions than in malignant lesions. Most naevi had a staining intensity of 1 (fig 3A-F). p-ERK was not detected in melanocytes of normal skin (fig 3G). p-ERK expression in thick melanomas was more intense towards the tumour margins, particularly the deep margin.

The IRS was estimated in the radial and vertical growth phases of primary melanoma (table 3). The correlation between p-ERK expression and histological subtypes of melanoma was also assessed. There was a higher percentage of cells positive for p-ERK in nodular melanomas than in compound naevi $(\mathrm{p}<0.0005)$, and a trend towards a higher percentage in nodular melanomas compared with superficial spreading melanomas ( $p=0.27$ ) (fig 4$)$. The relation of $p$ ERK to thickness or the dermal mitotic rate in the primary melanoma was also assessed. As shown in fig 5 there was a weak but not significant trend for p-ERK to be higher in thick melanoma $(\mathrm{p}=0.17)$ and there was also a trend towards

Table 2 ERK $1 / 2$ and $p$-ERK in the different types of melanocytic lesions

\begin{tabular}{|c|c|c|c|c|c|c|c|c|}
\hline \multirow[b]{2}{*}{ Melanocytic lesion } & \multirow{2}{*}{$\begin{array}{l}\text { Total no. in } \\
\text { each group }\end{array}$} & \multicolumn{2}{|c|}{ ERK $1 / 2$} & \multicolumn{3}{|l|}{ p-ERK } & \multicolumn{2}{|l|}{ p-ERK \% } \\
\hline & & $\%$ & IRS & No. positive & $\%$ & IRS & p Value* & p Valuet \\
\hline Compound naevus & 10 & 87.9 & 18.1 & $7 / 10$ & 32.4 & 4.2 & $\mathrm{CN} v$ thick, $<0.0001$ & $\mathrm{CN} v$ thick, $<0.0001$ \\
\hline Dysplastic naevus & 10 & 99.6 & 19.4 & $10 / 10$ & 54.5 & 5.5 & $\mathrm{DN} v$ thick, $<0.01$ & - \\
\hline \multicolumn{9}{|l|}{ Primary melanoma } \\
\hline Melanoma $\leqslant 1.0 \mathrm{~mm}$ & 18 & 98.9 & 24.5 & $18 / 18$ & 64.6 & 15.7 & Thin $v \mathrm{CN}, 0.05$ & - \\
\hline Melanoma $>1.0 \mathrm{~mm}$ & 24 & 84.1 & 17.2 & $24 / 24$ & 77.1 & 14.8 & Thick $v$ thin, 0.23 & Thick $v \mathrm{LN},<0.005$ \\
\hline Radial growth phase & 14 & 98.7 & 24.7 & $14 / 14$ & 61.7 & 15.4 & - & - \\
\hline Vertical growth phase & 28 & 86.3 & 21.6 & $28 / 28$ & 76.8 & 19.2 & - & - \\
\hline Subcutaneous metastasis & 21 & 93.1 & 23.7 & $21 / 21$ & 76.3 & 14.3 & $\mathrm{SC} \vee \mathrm{CN},<0.0005$ & $\mathrm{SC} v \mathrm{CN},<0.001$ \\
\hline Lymph node metastasis & 17 & 88.7 & 17.1 & $15 / 17$ & 48.5 & 9.0 & $\begin{array}{l}\text { LN } v \text { thick, }<0.005 \\
\text { LN } v \text { SC, }<0.005\end{array}$ & - \\
\hline
\end{tabular}

Subcutaneous metastases included two cases in fibrous fat tissue and one case in skeletal muscle.

Thick, melanoma $>1.0 \mathrm{~mm}$; thin, melanoma $\leqslant 1.0 \mathrm{~mm} ; \%$, mean percentage.

*Student's $t$ test; †Tukey-Kramer test for multiple comparisons.

CN, compound naevus; DN, dysplastic naevus; ERK, extracellular signal regulated kinase; IRS, immunoreactive score; LN, lymph node; p-ERK, activated extracellular signal regulated kinase; SC, subcutaneous. 


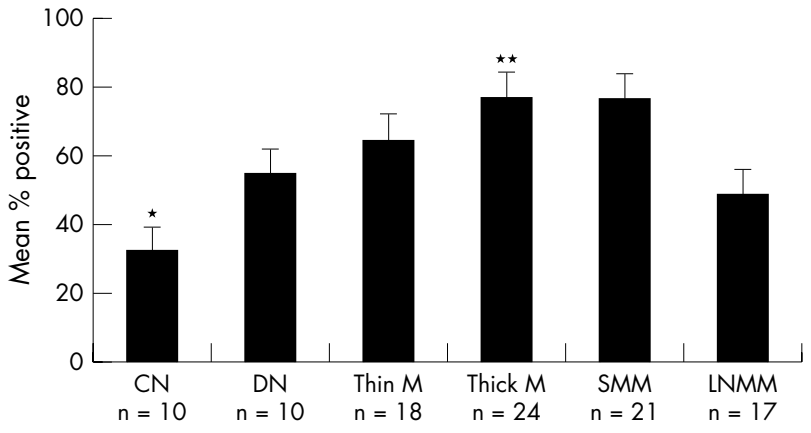

Types of melanocytic lesions

Figure 2 Mean percentage of cells positive for activated extracellular signal regulated kinase ( $p$-ERK) in different types of melanocytic lesions. $\mathrm{CN}$, compound naevus; DN, dysplastic naevus melanoma; LNMM, lymph node metastatic melanoma; $M$, melanoma; $S M M$, subcutaneous metastatic melanoma; thick, > $1.0 \mathrm{~mm}$; thin, $\leqslant 1.0 \mathrm{~mm}$. The $Y$ bar indicates one standard error. ${ }^{*} \mathrm{CN} v$ thick $\mathrm{M}, \mathrm{p}<0.0001$ (TukeyKramer); CN v SMM, $p<0.001$ (Tukey-Kramer); **thick M v LNMM, $p<0.005$.

increased p-ERK expression with increased dermal mitotic rate, although this was not significant ( $p=0.47$ ).

\section{DFS and OS}

During follow up of the 42 patients with primary cutaneous melanoma (median follow up 43.5 months), 15 patients developed recurrent melanoma. Among those, five had locoregional recurrences, two had distant metastases, and eight patients had both. Nine patients died with melanoma. No patients with melanoma $\leqslant 1 \mathrm{~mm}$ thickness had a recurrence or died (fig 6A). In patients with melanoma $>1 \mathrm{~mm}$ thickness there were trends for differences in DFS $\left(\chi^{2}=0.27, \mathrm{p}=0.6\right)$ and OS $\left(\chi^{2}=1.47, \mathrm{p}=0.23\right)$ in

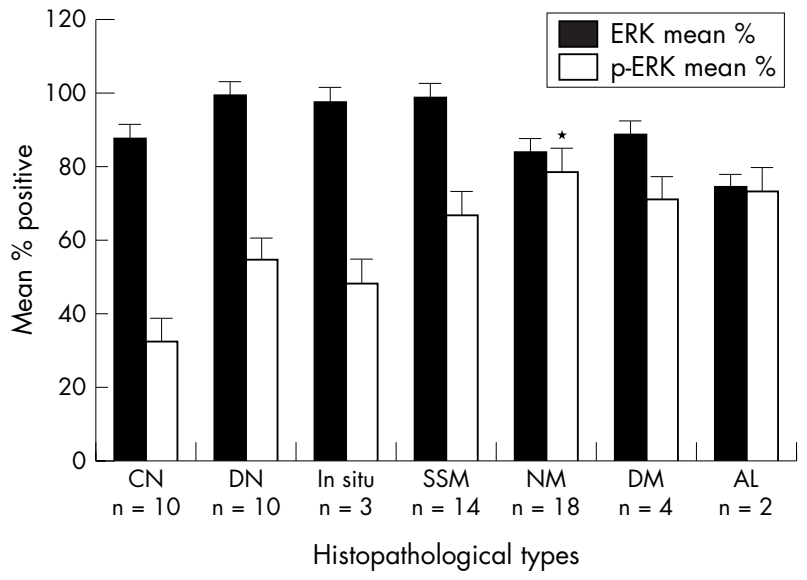

Figure 4 Mean percentage of cells positive for extracellular signal regulated kinase $1 / 2$ (ERK1/2) and p-activated ERK1/2 (p-ERK) in naevi and different histopathological types of primary melanoma. $\mathrm{AL}$, acral lentiginous; CN, compound naevus; DM, desmoplastic melanoma; DN, dysplastic naevus; NM, nodular melanoma; SSM, superficial spreading melanoma. *NM v CN, $\mathrm{p}<0.0005$ (Tukey-Kramer); NM $v$ SSM, $p=0.27$ (Tukey-Kramer)

patients with percentages of p-ERK positive cells above and below the median \% value $(80 \%)$ (fig $6 \mathrm{~B}$ ). There was no relation between IRS score and DFS or OS except when comparisons were made between survival in those with IRS scores $\leqslant 20$ (20 patients) or $>20$ (three patients) (DFS: $\chi^{2}=6.98, p=0.008$; OS: $\left.\chi^{2}=9.95, p=0.002\right)$. There was no significant difference between OS in patients with IRS scores above or below the median IRS of $15(\mathrm{p}=0.8)$. There were also no differences in DFS or OS at different cutoff values for percentage of p-ERK positive cells $(>50 \%$ / $\leqslant 50 \%,>60 \% / \leqslant 60 \%$, and $>70 \% / \leqslant 70 \%$; data not shown).
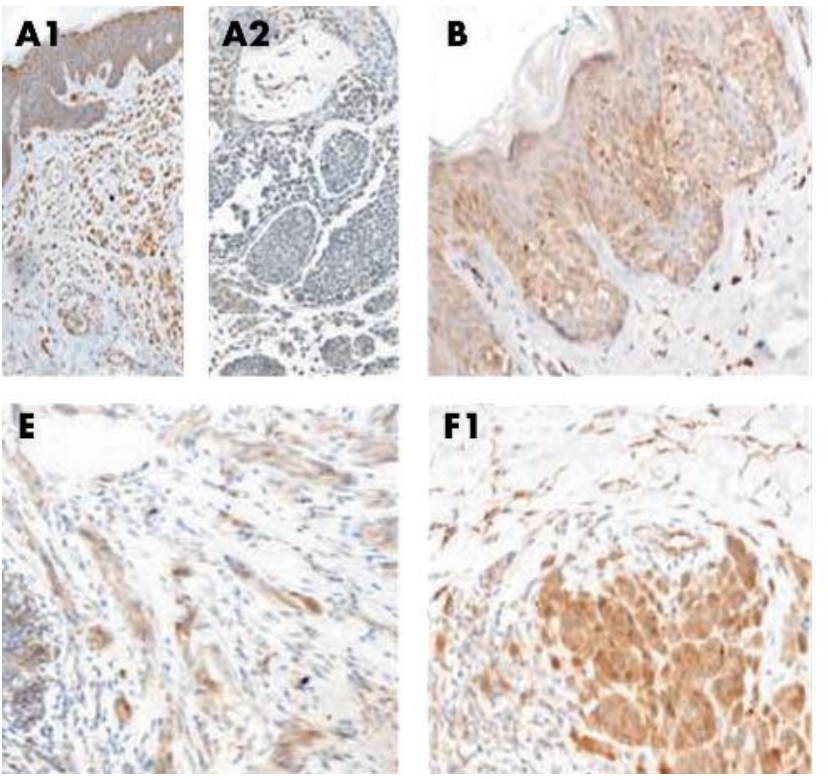
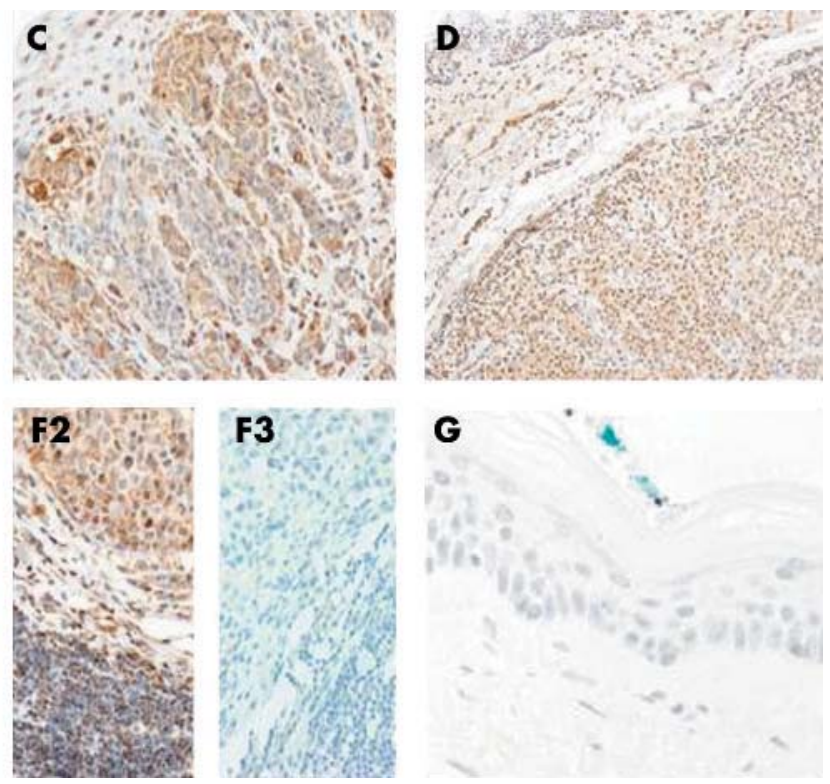

Figure 3 Activated extracellular signal regulated kinase ( $p-E R K)$ expression in different types of primary and secondary melanocytic tumours. (A) Compound naevus: (1) p-ERK(+); positive cells, 95\%; immunoreactive score (IRS), 9.5; original magnification, $\times 100$; (2) p-ERK(-); original magnification, $\times 200$. (B) Dysplastic naevus; positive cells, 50\%; IRS, 5; original magnification, $\times 200$. (C) Melanoma $\leqslant 1.0 \mathrm{~mm}$; positive cells, $97 \%$; IRS, 19.4; original magnification, $\times 200$. (D) Melanoma $>1.0 \mathrm{~mm}$; positive cells, $98 \%$; IRS, 24.5; original magnification, $\times 100$. (E) Desmoplastic melanoma; positive cells, 70\%; IRS, 7; original magnification, $\times 200$. (F) Metastatic melanoma: (1) subcutaneous metastasis; positive cells, 98\%; IRS, 19.6; original magnification, $\times 200$; (2) lymph node metastasis, $\mathrm{p}-\mathrm{ERK}(+)$; positive cells, $90 \%$; IRS, 18; original magnification, $\times 200$; (3) lymph node metastasis, $p$-ERK(-); original magnification, $\times 200$. (G) Normal skin melanocyłes; p-ERK(-); original magnification, $\times 400$. 


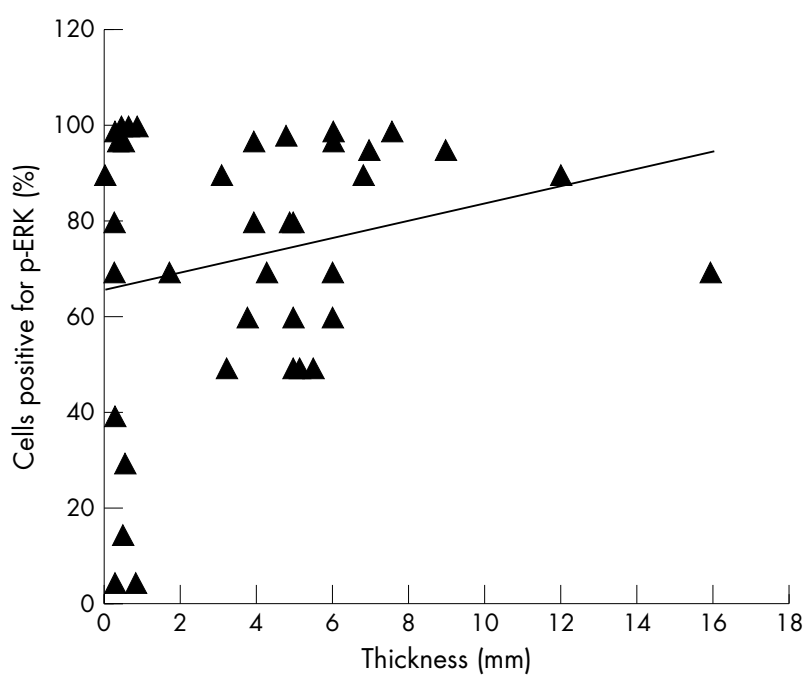

Figure 5 Percentage of activated extracellular signal regulated kinase ( $p$-ERK) positive tumour cells in primary melanoma correlated with tumour thickness. There was a trend towards increased $p$-ERK expression with increased tumour thickness, although this was not significant $\left(R^{2}=0.0454, \mathrm{p}=0.17\right)$.

\section{DISCUSSION}

In previous studies we found that activation of the ERKl/2 pathway inhibited apoptosis in a wide range of melanoma lines. Activation of this pathway is also known to be involved in regulation of the cell cycle through the retinoblastoma protein pathway. ${ }^{19}$ In view of these findings, we and others have hypothesised that activation of this pathway may be important in the development and progression of melanoma. ${ }^{1420}$ Our present study sought to obtain more evidence for this hypothesis by studies on sections of formalin fixed tissue that could not be influenced by in vitro manipulation and tissue culture.

The results showed that activated ERKl/2 (p-ERK) was found more frequently in primary melanoma than in naevi and that within naevi, p-ERK expression was higher in dysplastic naevi than in compound naevi. Within melanoma, nodular melanoma had higher expression than superficial spreading forms of melanoma. Therefore, increased expression of p-ERK correlated in general with the malignant potential of the lesions, ranging from compound naevi having low potential followed by dysplastic naevi, superficial spreading melanoma, and nodular melanoma. Further support for a relation with progression of melanoma was the finding that p-ERK was increased at the deeper margins of primary melanoma where the tumour was expanding and invading into the dermis.

"Increased expression of $\mathrm{p}$-ERK correlated in general with the malignant potential of the lesions, ranging from compound naevi having low potential followed by dysplastic naevi, superficial spreading melanoma, and nodular melanoma"

We examined whether p-ERK expression was related to other known prognostic features such as depth and mitotic rate of the primary tumour. There was a non-significant trend for the depth of melanoma to be associated with p-ERK expression, but there was no clear association with the mitotic rate. These results may indicate that other signalling pathways, such as the protein kinase B (Akt) pathway, ${ }^{19}$ are also involved, and that these impact on the mitotic rate, which was used as a measure of cell division in our study. The higher percentage of cells positive for p-ERK in nodular melanoma compared with benign naevi and superficial spreading melanoma is of interest because activating mutations of $\mathrm{N}$-ras (upstream of ERKl/2) have been reported to be more frequent in nodular melanoma and lentigo maligna melanomas. ${ }^{27}{ }^{28}$ Unfortunately, we were not able to assess $\mathrm{N}$ ras mutations in our samples. The expression of p-ERK in subcutaneous metastases was similar to that seen in thick melanoma, but an unexpected finding was the significantly lower percentage of tumour cells positive for p-ERK in 17 lymph node metastases (48.5\%) compared with metastases in subcutaneous sites $(76.3 \%)$ (Student's $t$ test, $\mathrm{p}<0.005$ ). An explanation for these findings is not readily apparent. Mutations of $\mathrm{N}$-ras and B-RAF were reported to be more frequent in cutaneous or soft tissue melanoma metastases, ${ }^{29}$ and this may in part account for the differences. Alternatively, it is possible that the microenvironment in lymph nodes inhibited activation of the ERKl/2 pathway. Further study of metastases at these sites is required to answer this question.

In addition to examining the correlation between p-ERK expression in melanoma and clinicopathological features, we

Table 3 Relation of p-ERK in primary melanoma (radial and vertical growth phases) to disease recurrence

\begin{tabular}{|c|c|c|c|c|c|c|}
\hline \multirow[b]{2}{*}{ Histopathological type (N) } & \multirow[b]{2}{*}{$\mathrm{N}$} & \multicolumn{2}{|c|}{ p-ERK } & \multirow{2}{*}{$\begin{array}{l}\text { Locoregional } \\
\text { recurrence }\end{array}$} & \multirow{2}{*}{$\begin{array}{l}\text { Distant recurrence } \\
\pm \text { local recurrence }\end{array}$} & \multirow[b]{2}{*}{ Deaths } \\
\hline & & $\%$ & IRS & & & \\
\hline \multicolumn{7}{|l|}{ Nodular (18) } \\
\hline RGP & 0 & 0 & 0 & 0 & 0 & 0 \\
\hline VGP & 18 & 78.8 & 14.7 & 4 & 5 & 4 \\
\hline \multicolumn{7}{|l|}{ Superficial spreading (14) } \\
\hline RGP & 10 & 63.9 & 15.8 & 0 & 0 & 0 \\
\hline VGP & 4 & 74.8 & 18.5 & 0 & 0 & 0 \\
\hline \multicolumn{7}{|l|}{ Desmoplastic (4) } \\
\hline RGP & 0 & 0 & 0 & 0 & 0 & 0 \\
\hline VGP & 4 & 71.3 & 15.8 & 1 & 3 & 3 \\
\hline \multicolumn{7}{|l|}{ In situ (3) } \\
\hline RGP & 3 & 48.3 & 13 & 0 & 0 & 0 \\
\hline VGP & 0 & 0 & 0 & 0 & 0 & 0 \\
\hline \multicolumn{7}{|l|}{ Acral lentiginous (2) } \\
\hline RGP & 0 & 0 & 0 & 0 & 0 & 0 \\
\hline VGP & 2 & 73.5 & 13.5 & 0 & 2 & 2 \\
\hline \multicolumn{7}{|l|}{ Lentigo maligna (1) } \\
\hline RGP & 1 & 80 & 12 & 0 & 0 & 0 \\
\hline VGP & 0 & 0 & 0 & 0 & 0 & 0 \\
\hline Total & 42 & & & 5 & 10 & 9 \\
\hline
\end{tabular}

IRS, immunoreactive score; p-ERK, activated extracellular signal regulated kinase; RGP, radial growth phase; VGP, vertical growth phase; \%, mean percentage. 

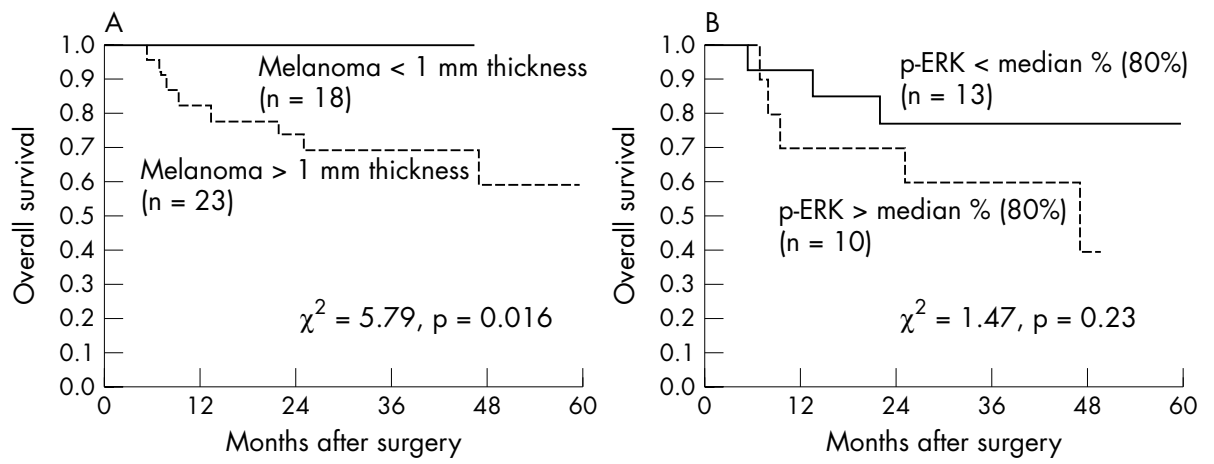

Figure 6 Kaplan-Meier estimates of overall survival (OS) after excision of primary cutaneous melanoma. (A) OS of patients with melanoma $\leqslant 1 \mathrm{~mm}$ thickness versus $>1 \mathrm{~mm}$ thickness. (B) OS of patients with thick melanoma having \% activated extracellular signal regulated kinase ( $p$-ERK) below the median value $(\leqslant 80 \%)$ versus patients with values above the median $(>80 \%)$.

tested its association with DFS and OS in patients with primary melanoma. There were no recurrences or deaths in patients with thin melanoma $(\leqslant 1 \mathrm{~mm})$, but in patients with melanoma $>1 \mathrm{~mm}$ thickness, those with p-ERK \% values above the median tended to have a lower OS than those with values below the median $(\mathrm{p}=0.23)$. These findings provide further support for the view that activation of ERKl/2 is related to the progression of melanoma. However, the patient numbers in our study were small and did not warrant multivariate analysis of the data.

The mechanisms underlying activation of the ERKl/2 kinases are not clear. ERKl/2 kinases may be activated by ligand interaction with tyrosine kinase receptors via RAS kinase, RAF kinase, and MAPK kinase or by crosstalk with the protein kinase $\mathrm{C}$ pathway. ${ }^{20}{ }^{30}$ Therefore, it is possible that paracrine or autocrine growth factors, such as fibroblast growth factor ${ }^{31}$ or chemokines, ${ }^{29}$ are responsible for activation of the pathway. Activating mutations of B-RAF upstream of ERKl/2 are relatively common in melanoma and naevi. ${ }^{32-35}$ If this was the only factor involved, p-ERK would be expected to be expressed equally in naevi and melanomas, which was not the case in our study or in other studies. It has been found that transfection of mutated B-RAF into melanocytes results in activation of ERK1/2 $2^{30}$ but $\mathrm{B}-R A F$ is not required for signalling by mutated $\mathrm{N}$-ras. $\mathrm{N}$-ras mutations are believed to be infrequent in melanoma (occurring in approximately $11 \%) .{ }^{36}$ In addition, studies by others have shown that divergent pathways may exist upstream of ERKl/2. ${ }^{37}$ Interestingly, high amounts of p-ERK are seen in Spitz naevi, but these lesions usually have a low mitotic rate, possibly because of high concentrations of pl6 cell cycle inhibitory proteins. $^{38}$

\section{Take home messages}

- The expression of activated extracellular regulated kinase $1 / 2$ (ERK1/2) appears to be related to malignant potential in melanocytic lesions

- Activation of ERK1/2 may be important in melanoma progression

- Our results support the hypothesis that activation of the ERK1/2 signalling pathway in melanoma may confer resistance to apoptosis and subsequent resistance to treatment

- Inhibition of this signalling pathway may be useful in the treatment of melanoma
Irrespective of the cause of ERK activation in melanoma, our data support the concept that inhibition of this cell signalling pathway might be useful in the treatment of melanoma. ${ }^{39-42}$ Our previous studies showing the importance of ERK1/2 in the resistance of melanoma to apoptosis ${ }^{14}$ also indicate that this pathway may be an important target in the treatment of melanoma with apoptosis inducing agents. This has been supported by the promising results of studies in preclinical models with the MAPK kinase inhibitor CI1040, ${ }^{43}$ and phase I/II studies in patients treated with Carboplatin and Paclitaxel together with the Bayer BRAF inhibitor, BAY 43-9006. ${ }^{44}$ Our present study suggests that approximately $90 \%$ of patients with metastatic disease have some degree of activation of this pathway and hence may benefit from this treatment approach.

\section{ACKNOWLEDGEMENTS}

We thank the staff of the Department of Anatomical Pathology, Royal Prince Alfred Hospital, especially S Davies and D Maguire, for their assistance with immunohistochemistry; the staff of the Oncology and Immunology Unit of the Newcastle Mater Misericordiae Hospital for their assistance and comments; and M Colman from the Sydney Melanoma Unit Database for follow up information.

\section{Authors' affiliations}

L Zhuang, C S Lee, R A Scolyer, S W McCarthy, A A Palmer, Department of Anatomic Pathology, Royal Prince Alfred Hospital, Sydney, New South Wales, Australia

J F Thompson, L P Bron, Sydney Melanoma Unit and the Melanoma and Skin Cancer Research Institute, Royal Prince Alfred Hospital X D Zhang, P Hersey, Oncology and Immunology Unit, Newcastle Mater Misericordiae Hospital, Newcastle, NSW 2300, Australia

\section{REFERENCES}

1 Armstrong B. Epidemiology of cutaneous melanoma and current trends. London: Martin Dunitz, 2004.

2 Coates M, Tracey E. Cancer in New South Wales: incidence and mortality 1997. N S W Public Health Bull 2001;12:40-2.

3 Azzola MF, Shaw HM, Thompson JF, et al. Tumor mitotic rate is a more powerful prognostic indicator than ulceration in patients with primary cutaneous melanoma: an analysis of 3661 patients from a single center. Cancer 2003;97:1488-98

4 Balch CM, Soong SJ, Gershenwald JE, et al. Prognostic factors analysis of 17,600 melanoma patients: validation of the American Joint Committee on Cancer melanoma staging system. J Clin Oncol 2001;19:3622-34.

5 McKinnon JG, Yu XQ, McCarthy WH, et al. Prognosis for patients with thin cutaneous melanoma: long-term survival data from New South Wales Central Cancer Registry and the Sydney Melanoma Unit. Cancer 2003;98:1223-31.

6 Eigentler TK, Caroli UM, Radny P, et al. Palliative therapy of disseminated malignant melanoma: a systematic review of 41 randomised clinical trials. Lancet Oncol 2003;4:748-59.

7 Penn LZ. Apoptosis modulators as cancer therapeutics. Curr Opin Investig Drugs 2001;2:684-92.

8 Soengas MS, Lowe SW. Apoptosis and melanoma chemoresistance. Oncogene 2003;22:3138-51. 
9 Cory S, Adams JM. The Bcl2 family: regulators of the cellular life-or-death switch. Nat Rev Cancer 2002;2:647-56.

10 Green DR, Evan GI. A matter of life and death. Cancer Cell 2002;1:19-30.

11 Hussein MR, Haemel AK, Wood GS. Apoptosis and melanoma: molecular mechanisms. J Pathol 2003;199:275-88.

12 Hersey $P$, Zhang XD. Overcoming resistance of cancer cells to apoptosis. J Cell Physiol 2003;196:9-18.

13 Bogenrieder T, Herlyn M. Biology of melanoma: molecular and cellular biology, 3rd ed. New York: Lippincott, 2003.

14 Zhang XD, Borrow JM, Zhang XY, et al. Activation of ERK1/2 protects melanoma cells from TRAIL-induced apoptosis by inhibiting Smac/DIABLO release from mitochondria. Oncogene 2003;22:2869-81.

15 Cobb MH. MAP kinase pathways. Prog Biophys Mol Biol 1999;71:479-500.

16 Arbiser JL, Weiss SW, Arbiser ZK, et al. Differential expression of active mitogen-activated protein kinase in cutaneous endothelial neoplasms: implications for biologic behavior and response to therapy. J Am Acad Dermatol 2001;44:193-7.

17 Cohen C, Zavala-Pompa A, Sequeira JH, et al. Mitogen-activated protein kinase activation is an early event in melanoma progression. Clin Cancer Res 2002;8:3728-33.

18 Govindarajan B, Bai X, Cohen C, et al. Malignant transformation of melanocytes to melanoma by constitutive activation of mitogen-activated protein kinase kinase (MAPKK) signaling. J Biol Chem 2003;278:9790-5.

19 Massague J. G1 cell-cycle control and cancer. Nature 2004:432:298-306.

20 Smalley KS. A pivotal role for ERK in the oncogenic behaviour of malignant melanoma? Int J Cancer 2003;104:527-32.

21 Elder DE. Atlas of tumour pathology. Melanocytic tumors of the skin, 3rd Series, Fascicle 2. Washington, DC: Armed Forces Institute of Pathology, 1991.

22 Weedon D. Skin pathology, 2nd ed. London: Churchill Livingstone, 2002.

23 Shi S-R, Gu J, Taylor CR. Immunohistochemistry and molecular morphology. USA: Eaton Publishing, 2000.

24 Wang S, Wang S, Zhu X, et al. [Significance of MEK-ERK cascade in the development of human breast carcinoma.] Zhonghua Wai Ke Za Zhi 2002;40:171-4.

25 Royuela M, Arenas MI, Bethencourt FR, etal. Regulation of proliferation/apoptosis equilibrium by mitogen-activated protein kinases in normal, hyperplastic, and carcinomatous human prostate. Hum Pathol 2002;33:299-306.

26 Cox D. Regression models and life tables (with discussion). Journal of the Royal Statistical Society of Britain 1972;34:187-220.

27 Van Elsas A, Zerp SF, van der Flier S, et al. Relevance of ultraviolet-induced $\mathrm{N}$-ras oncogene point mutations in development of primary human cutaneous melanoma. Am J Pathol 1996;149:883-93.
28 Jafari M, Papp T, Kirchner S, et al. Analysis of ras mutations in human melanocytic lesions: activation of the ras gene seems to be associated with the nodular type of human malignant melanoma. J Cancer Res Clin Oncol 1995; 121:23-30.

29 Houben R, Becker JC, Kappel A, et al. Constitutive activation of the Ras-Raf signaling pathway in metastatic melanoma is associated with poor prognosis. $J$ Carcinog 2004;3:6.

30 Chuderland D, Seger R. Protein-protein interactions in the regulation of the extracellular signal-regulated kinase. Mol Biotechnol 2005;29:57-74.

31 Satyamoorthy K, Li G, Gerrero MR, et al. Constitutive mitogen-activated protein kinase activation in melanoma is mediated by both BRAF mutations and autocrine growth factor stimulation. Cancer Res 2003;63:756-9.

32 Davies $\mathrm{H}$, Bignell GR, Cox $\mathrm{C}$, et al. Mutations of the BRAF gene in human cancer. Nature 2002;417:949-54.

33 Pavey S, Johansson P, Packer L, et al. Microarray expression profiling in melanoma reveals a BRAF mutation signature. Oncogene 2004;23:4060-7.

34 Pollock PM, Harper UL, Hansen KS, et al. High frequency of BRAF mutations in nevi. Nat Genet 2003;33:19-20.

35 Pruitt K, Der CJ. Ras and Rho regulation of the cell cycle and oncogenesis. Cancer Lett 2001;171:1-10.

36 Wellbrock C, Ogilvie L, Hedley D, et al. V599EB-RAF is an oncogene in melanocytes. Cancer Res 2004;64:2338-42.

37 Brognard J, Dennis PA. Variable apoptotic response of NSCLC cells to inhibition of the MEK/ERK pathway by small molecules or dominant negative mutants. Cell Death Differ 2002;9:893-904.

38 Maldonado JL, Timmerman L, Fridlyand J, et al. Mechanisms of cell-cycle arrest in Spitz nevi with constitutive activation of the MAP-kinase pathway. Am J Pathol 2004;164:1783-7.

39 Adjei AA. Signal transduction pathway targets for anticancer drug discovery. Curr Pharm Des 2000;6:361-78.

40 Adjei AA. Ras signaling pathway proteins as therapeutic targets. Curr Pharm Des 2001;7:1581-94.

41 Adjei AA. Blocking oncogenic Ras signaling for cancer therapy. J Natl Cancer Inst 2001;93:1062-74.

42 Ghobrial IM, Adjei AA. Inhibitors of the ras oncogene as therapeutic targets. Hematol Oncol Clin North Am 2002; 16:1065-88.

43 Collisson EA, De A, Suzuki H, et al. Treatment of metastatic melanoma with an orally available inhibitor of the Ras-Raf-MAPK cascade. Cancer Res 2003;63:5669-73.

44 Hotte SJ, Hirte HW. BAY 43-9006: early clinical data in patients with advanced solid malignancies. Curr Pharm Des 2002;8:2249-53. 